\title{
Analisis Rantai Markov Untuk Memprediksi Perpindahan Merek Shampoo Di Hypermart Swalayan Manado Town Square
}

\author{
${ }^{1}$ Djini Tamudia, ${ }^{2}$ Johanes Langi, ${ }^{3}$ Julia Titaley \\ ${ }^{1}$ Program Studi Matematika, FMIPA, UNSRAT, djinitamudia@gmail.com \\ ${ }^{2}$ Program Studi Matematika, FMIPA, UNSRAT, yarlangi@gmail.com \\ ${ }^{3}$ Program Studi Matematika, FMIPA, UNSRAT, july_titaley@ yahoo.com
}

\begin{abstract}
This research has been conducted to determine the changes of consumers switching between brand of Shampoo and make predictions of consumer migration opportunities of each brand Shampoo among customer in the future. The data used in this study is primary data colleted through a questionnaire on the 100 customer of Hypermart swalayan Manado Town Square on July to September 2013. Data were analyzed by Markov Chains analysis. Base on Markov Chains analysis, it is found that Sunsilk consumen as a large percentage of consumen in early and even in later years with a value $25 \%$. On the second level brand Pantene reach a value 16\% and the lowest level brand Lifeboy, Clear and other brand only able to reach 4\%.
\end{abstract}

Keywords : Brand Switching, Consumen, Markov Chains

\begin{abstract}
Abstrak
Telah dilakukan penelitian untuk mengetahui peluang perpindahan konsumen merek shampoo ke merek shampoo lainnya serta membuat prediksi peluang perpindahan konsumen merek shampoo pada pelanggan Hypermart Swalayan Manado Town Square dimasa yang akan datang. Data yang digunakan adalah data primer yang dikumpulkan melalui penyebaran kuesioner pada 100 orang pelanggan Hypermart Swalayan Manado Town Square pada bulan Juli sampai September 2013. Data yang diperoleh dianalisis dengan rantai Markov. Berdasarkan hasil analisis Rantai Markov, diperoleh pengguna merek shampoo Sunsilk memiliki presentasi terbanyak dan bahkan untuk tahun-tahun berikutnya yaitu 25\%. Pada urutan kedua merek shampoo Pantene dengan presentasi 16\% dan urutan yang terendah adalah merek shampoo Lifeboy, Clear dan merek shampoo lainnya dengan presentasi $4 \%$.
\end{abstract}

Kata kunci : Pengguna Shampoo, Perpindahan Merek, Rantai Markov

\section{Pendahuluan}

Persaingan dunia industri yang semakin pesat saat ini mendorong setiap perusahaan untuk mampu bersaing dengan mengedepankan produk berupa barang atau jasa yang ditawarkannya. Pengadaan berbagai macam produk atau barang pada suatu pasar sangat mempengaruhi perilaku konsumen untuk mau mendatangi dan membeli barang yang terdapat dalam pasar tersebut. Keinginan konsumen untuk memenuhi kebutuhan sehari-hari menjadi satu alasan yang kuat untuk membeli produk atau barang yang dibutuhkannya sehari-hari [5].

Shampoo, seperti yang kita ketahui merupakan barang kebutuhan sehari-hari dan hampir seluruh lapisan masyarakat mengkonsumsinya. Industri shampoo Indonesia bertumbuh dan berkembang mengikuti perkembangan perekonomian Indones ia setiap tahunnya.

Agar konsumen tidak beralih ke produk sejenis dengan merek lain, produsen harus mampu menciptakan produk dengan atribut-atribut yang sesuai dengan kebutuhan dan keinginan konsumen. Selain itu, produsen juga harus mampu menganalisa faktor-faktor yang menjadi sebab konsumen memilih merek tertentu. Dengan atribut-atribut dan faktor-faktor tersebut produsen akan mampu menciptakan citra yang baik pada produknya sehingga mampu memenuhi kebutuhan dan keinginan konsumen untuk menguasai pangsa pasar. Oleh karena itu, perlu adanya prediksi market share agar tingkat penjualan dapat optimal. Dengan adanya masalah tersebut maka dilakukan penelitian dengan menggunakan metode Rantai Markov yang diperkenalkan oleh matematikawan asal Rusia A. A. Markov (1856-1922) untuk memprediksi market share masing-masing produk shampoo. 


\section{Analis is Rantai Markov}

\section{Definisi 1 (Ruang State)}

Misalnya $S$ adalah himpunan nilai dari barisan peubah acak, maka $S$ disebut ruang state [2].

\section{Definisi 2 (Prosese Stokastik)}

Proses stokastik $X=\{X(t), t \in T\}$ adalah suatu himpunan dari peubah acak yang memetakan suatu ruang contoh $\Omega$ ke suatu ruang state $S[8]$

Definisi 3 (Rantai Markov)

Andaikan terdapat suatu peluang tetap $P_{i j}$ yang bersifat bebas terhadap waktu maka berlaku

dimana $i=$ state $\mathrm{ke}-i$

$$
P\left\{X_{t+1}=j \mid X_{0}=i_{0}, \ldots, X_{t-1}=i_{t-1}, X_{t}=i\right\}=P\left\{X_{t+1}=j \mid X_{t}=i\right\}
$$

$j=$ state $\mathrm{ke}-j$

$\mathrm{t}=$ waktu

$i_{0}, \ldots, i_{t-1}, i_{j} j$ dan semua $t \geq 0[1]$.

Definisi 4 (Matriks Peluang Transisi)

Jika sebuah rantai Markov $\left\{X_{\mathrm{t}}, \mathrm{t}=0,1,2, \ldots\right\}$ dengan ruang state $\{0,1, \ldots, \mathrm{M}\}$, maka peluang sistem itu dalam state $i$ pada suatu state $j$ pada pengamatan sebelumnya dilambangkan dengan $P_{i j}$ dan disebut peluang transisi dari state $i$ ke state $j$. Matirks $\mathbf{P}=\left[\mathrm{p}_{\mathrm{ij}}\right]$ disebut matriks transisi rantai Markov. Dimana elemen-elemen dari matriks $\mathbf{P}$ bernilai positif dan jumlah elemen-elemen pada satu baris di matriks peluang transisi ini harus sama dengan1 [4]. Jadi,

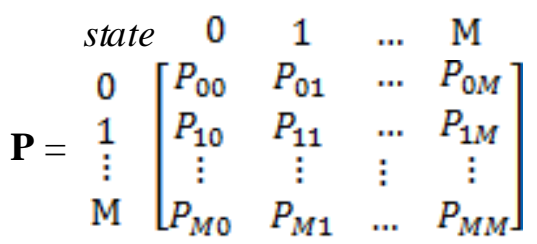

\subsection{Vektor Keadaan (State Vektor)}

State atau keadaan pada rantai Markov yang ditulis dalam bentuk vektor yang dinamakan vektor state (state vector). Vektor state untuk sebuah pengamatan pada suatu rantai Markov dengan $X(t)$ state adalah vektor baris $x$, dapat dituliskan

$$
\boldsymbol{x}=\left[x_{1}, x_{2}, \ldots, x_{i}\right]
$$

dimana, $x_{1}$ adalah peluang sistem tersebut berada pada state 1 .

$x_{2}$ adalah peluang sistem tersebut berada pada state 2 .

$x_{i}$ adalah peluang sistem tersebut berada pada state $i$.

Jika $\mathbf{P}$ merupakan matriks transisi rantai Markov dan $x^{(n)}$ adalah vektor state pada pengamatan ke- $n$, maka

$$
x^{(n)}=\mathbf{P}^{\mathbf{n}} x^{0}
$$

dimana $x^{0}$ merupakan matriks kejadian $\left[x_{1}, x_{2}, \ldots, x_{i}\right]$.

\subsection{Analis is Deskriptif}

Metode dalam analisis deskriptif ini menyangkut cara-cara menghimpun, menyusun atau mengatur, mengolah, menyajikan dan menganalis is data angka agar dapat memberikan gambaran teratur, ringkas dan jelas mengenai suatu gejala, peristiwa atau keadaan sehingga memperoleh pengertian atau makna tertentu. Metode-metode dalam analisis deskriptif ini mencakup atas distribusi frekuensi, nilai rata-rata dan ukuran penyebaran data [7].

Penilaian reponden terhadap 8 atribut atribut jasa yang diberikan terdiri dari harga yang murah, produk tertentu, bentuk kemasan yang menarik, isi produk yang memuaskan, hasil yang bagus, keharuman produk, manfaat yang bagus, komposisi unsur yang bervariasi, promosi/ik lan yang menarik. Penilaian responden terhadap atribut ini diukur dari dengan skor terendah yaitu 1 
dan skor yang tertinggi yaitu 10, dimana untuk skor 1 sampai dengan 3 merupakan skor terendah, skor 4 sampai dengan 7 merupakan skor penilaian cukup dan skor 8 sampai dengan 10 merupakan skor penilaian yang tinggi pada atribut [3].

\section{Metode Penelitian}

Objek yang diambil adalah 9 merek shampoo dewasa yaitu Sunsilk, Pantene,Tresemme, Rejoice, Head \&Shoulders, Dove, Loreal, Clear, Lifeboy dan merek shampoo yang tidak termasuk ke dalam sembilan merek shampoo dimasukkan kedalam merek shampoo lainnya. Data merupakan data primer yang diambil dari penyebaran kuesioner kepada 100 pelanggan wanita di Hypermart Swalayan Manado Town Square.

Langkah - langkah untuk menyelesaikan penelitian ini adalah:

1. Pengumpulan data

2. Membuat analis is deskriptif kuantitatif untuk mengklasifikasi jawaban responden terhadap alasan pengguna merek shampoo

3. Membuat tabel perpindahan merek shampoo

4. Menentukan is i atau nilai-nilai da lam matriks peluang transisi dari analis is rantai Markov yang diperoleh dari tabel perpindahan merek (Brand Switching Pattern).

5. Membuat prediksi jumlah konsumen dari setiap merek shampoo untuk tahun 2014 sampai dengan 2016 menggunakan software QM(Quantitative Method) v.2.2.

\section{Hasil Dan Pembahasan}

\subsection{Analis is Desk riptif}

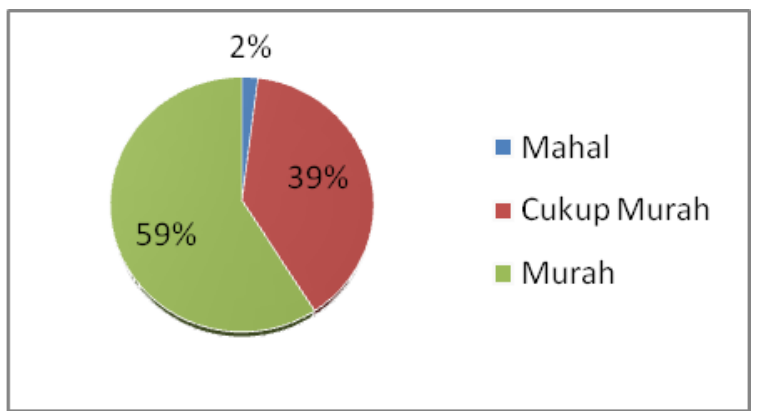

(a)

Gambar 1. Penilaian Responden Terhadap Atribut Harga

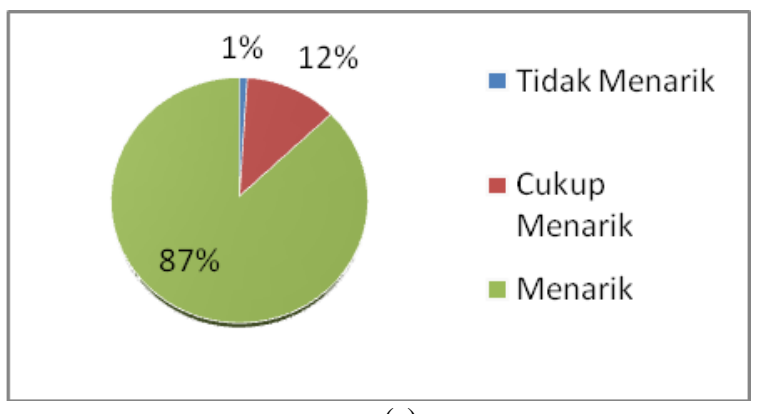

(c)

Gambar 3. Penilaian Responden Terhadap Atribut Bentuk Kemasan

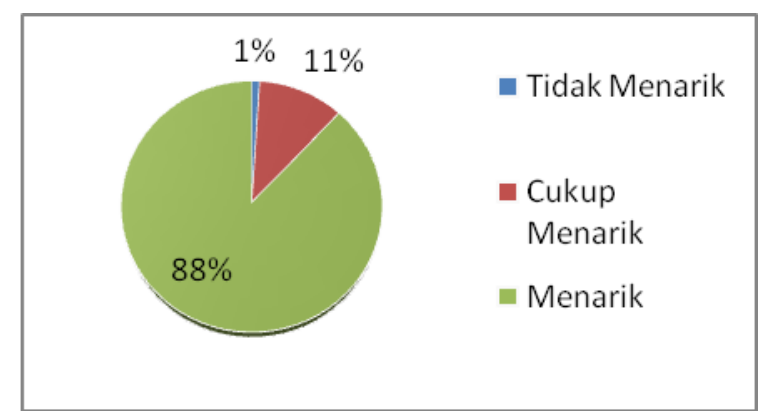

(b)

Gambar 2. Penilain Responden Terhadap Atribut Merek

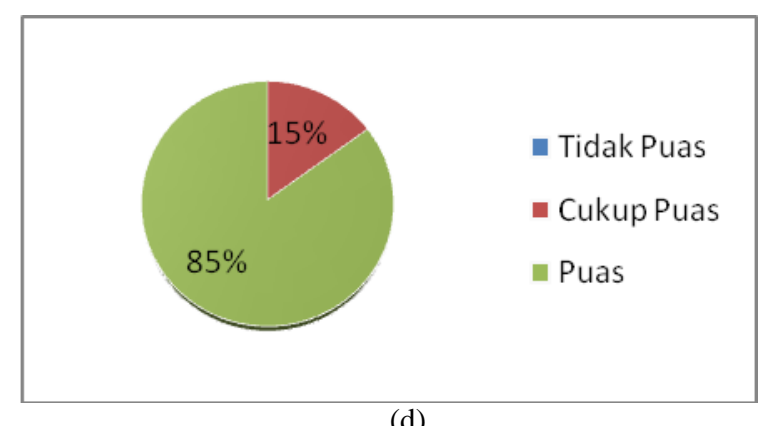

Gambar 4. Penilaian Responden Terhadap Atribut Isi 


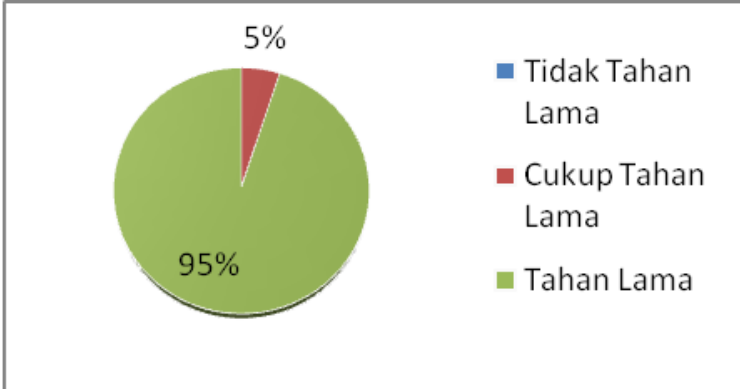

(e)

Gambar 5. Penilaian Responden Terhadap Atribut Keharuman

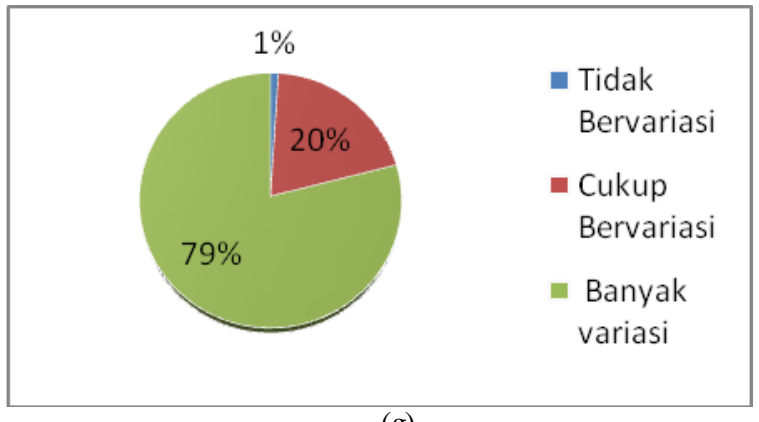

(g)

Gambar 7. Penilaian Responden Terhadap Atribut Variasi Komposisi Unsur

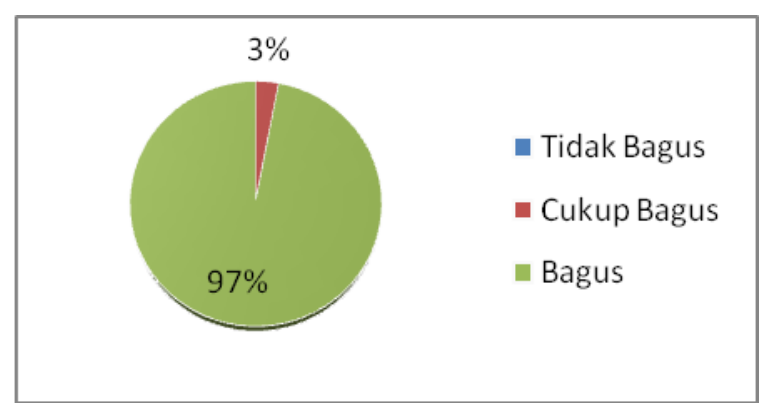

(f)

Gambar 6. Penilaian Responden Terhadap Atribut Manfaat

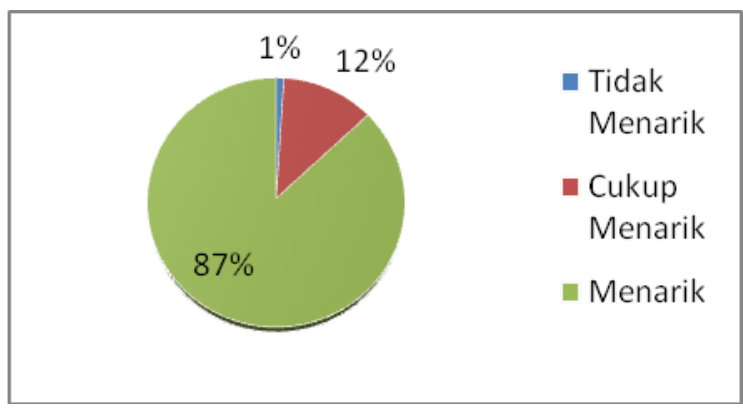

(h)

Gambar 8. Penilaian Responden Terhadap Atribut Iklan

Alasan pelanggan Hypermart Swalayan MANTOS menggunakan merek shampoo dilihat dari penilaian masing-masing atribut yang diberikan dimana $88 \%$ menilai produk yang digunakan menarik, 59\% harga yang murah, $87 \%$ bentuk kemasan yang menarik, $85 \%$ puas dengan isi poduk, 97\% manfaat yang bagus, $87 \%$ iklan yang menarik, $79 \%$ produk yang digunakan bervariasi.

\subsection{Analisis Rantai Markov}

Tabel 1. Ju mlah Pengguna Merek Shampoo Sekarang dan Sebelu mnya

\begin{tabular}{|c|l|c|c|c|c|}
\hline No. & Merek Shampoo & $\begin{array}{c}\text { Jumlah } \\
\text { Konsumen } \\
\text { Sebelumnya }\end{array}$ & $\begin{array}{c}\text { Perolehan } \\
\text { (Orang) }\end{array}$ & $\begin{array}{c}\text { Kehilangan } \\
\text { (Orang) }\end{array}$ & $\begin{array}{c}\text { Jumlah } \\
\text { Konsumen } \\
\text { Sekarang }\end{array}$ \\
\hline 1 & Sunsilk & 27 & 17 & 19 & 25 \\
\hline 2 & Pantene & 26 & 12 & 22 & 16 \\
\hline 3 & Tresemme & 3 & 8 & 3 & 8 \\
\hline 4 & Rejoice & 11 & 7 & 10 & 8 \\
\hline 5 & Head \& Shoulders & 3 & 5 & 3 & 5 \\
\hline 6 & Dove & 11 & 12 & 11 & 12 \\
\hline 7 & Loreal & 5 & 14 & 5 & 14 \\
\hline 8 & Clear & 6 & 4 & 6 & 4 \\
\hline 9 & Lifeboy & 4 & 4 & 4 & 4 \\
\hline 10 & Lainnya & 4 & 4 & 4 & 4 \\
\hline \multicolumn{2}{|l}{ Jumlah } & 100 & 87 & 87 & 100 \\
\hline
\end{tabular}

Tabel 1 menunjukkan bahwa merek shampoo Sunsilk adalah merek yang paling banyak digunakan oleh responden dengan jumlah 25 orang. Selanjutnya merek shampoo Pantene diurutan kedua terbanyak yang digunakan oleh 16 orang responden dan merek shampoo Loreal pada urutan 
ketiga dengan jumlah responden 14 orang, selanjutnya merek shampoo Dove dengan jumlah responden 12 orang dan urutan kelima yaitu merek shampoo Tresemme dan Rejoice dengan jumlah responden 8 orang, kemudian urutan keenam adalah merek shampoo Head \& Shoulders dengan jumlah responden 5 orang dan merek shampoo Clear, Lifeboy serta merek shampoo lainnya berada diurutan terakhir dengan jumlah responden 4 orang.

Tabel 2. Pola Perpindahan Merek (Brand Switching Pattern )

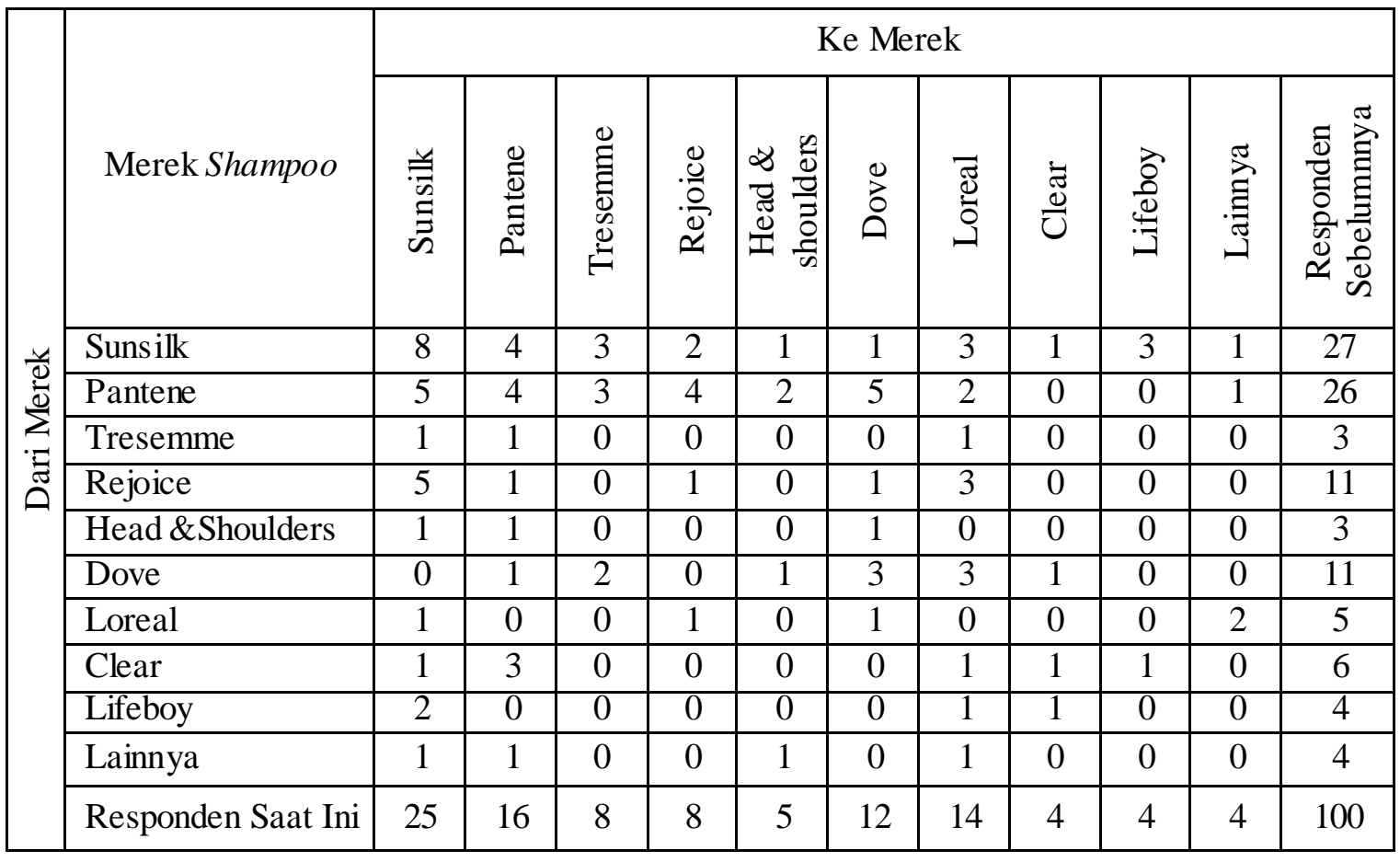

Pada Tabel 2 terlihat merek shampoo Sunsilk saal ini digunakan oleh 25 orang konsumen dimana ada 8 orang konsumen yang tetap menggunakan merek shampoo Sunsilk, konsumen yang berpindah dari merek shampoo Pantene dan Rejoice masing-masing 5 orang, dari merek shampoo Lifeboy 2 orang dan dari merek shampoo Tresemme, Head \& Shoulders, Loreal, Clear, serta merek shampoo lainnya masing-masing 1 orang.

Merek shampoo Pantene pada saat ini digunakan oleh 16 orang konsumen dimana ada 4 orang konsumen yang tetap menggunakan merek shampoo Pantene dan konsumen yang berpindah dari merek Sunsilk 4 orang, Clear 3 orang dan dari merek shampoo Tresemme, Rejoice, Head \& Shoulders serta merek shampoo lainnya masing-masing 1 orang.

Merek shampoo Tresemme pada saat ini digunakan oleh 8 orang konsumen dimana konsumen yang berpindah dari merek Sunsilk 3 orang, Pantene 3 orang, dan dari merek shampoo Dove 3 orang.

Merek shampoo Rejoice pada saat ini digunakan oleh 8 orang konsumen dimana ada 1 orang konsumen yang tetap menggunakan merek shampoo Rejoice dan konsumen yang berpindah dari merek Sunsilk 2 orang, Pantene 4 orang dan dari merek shampoo Loreal 1 orang.

Merek shampoo Head \& Shoulders pada saat ini digunakan oleh 5 orang konsumen, konsumen yang berpindah dari merek Pantene 2 orang dan dari merek shampoo Sunsilk, Dove serta merek shampoo lainnya masing-masing 1 orang.

Merek shampoo Dove pada saat ini digunakan oleh 12 orang konsumen dimana ada 3 orang konsumen yang tetap menggunakan merek shampoo Dove dan konsumen yang berpindah dari merek Pantene 5 orang dan dari merek shampoo Sunsilk, Rejoice, Head \& Shoulders, Loreal masing-masing 1 orang.

Merek shampoo Loreal pada saat ini digunakan oleh 14 orang konsumen dimana konsumen yang berpindah dari merek Sunsilk 3 orang, Pantene 2 orang, Rejoice 3 orang, Dove 3 orang dan merek shampoo Tresemme, Clear, Lifeboy serta merek shampoo lainnya masing-masing 1 orang. 
Merek shampoo Clear pada saat ini digunakan oleh 4 orang konsumen dimana ada 1 orang konsumen yang tetap menggunakan merek shampoo Clear dan konsumen yang berpindah dari merek Sunsilk 1 orang, Dove 1 orang, dan dari merek shampoo Lifeboy 1 orang.

Merek shampoo Lifeboy pada saat ini digunakan oleh 4 orang konsumen, konsumen yang berpindah dari merek Sunsilk 3 orang dan dari merek shampoo Clear 1 orang.

Merek shampoo lainnya pada saat ini digunakan oleh 4 orang konsumen, konsumen yang berpindah dari merek Sunsilk 1 orang, Pantene 1 orang dan dari merek shampoo Loreal 2 orang.

Selanjutnya dari Tabel 2 dibuat tabel peluang transisi yang dapat dilihat pada Tabel 3.

Tabel 3. Peluang Transisi (P)

\begin{tabular}{|c|c|c|c|c|c|c|c|c|c|c|}
\hline \multirow[b]{2}{*}{ Dari Merek } & \multicolumn{10}{|c|}{ Ke Merek } \\
\hline & 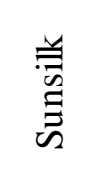 & 离 & 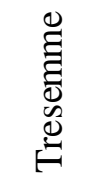 & $\frac{0}{\frac{0}{0}}$ & 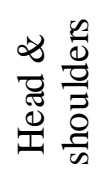 & 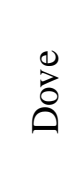 & ॠ్ & $\frac{\bar{\Xi}}{\tilde{U}}$ & 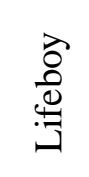 & 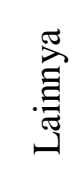 \\
\hline Suns ilk & $\overline{0,3}$ & 0,15 & 0,11 & 0,07 & 0,04 & 0,04 & ,011 & 0,04 & 0,11 & 0,04 \\
\hline Pantene & 0,19 & 0,15 & 0,12 & 0,15 & 0,08 & 0,19 & 0,08 & 0 & 0 & 0,04 \\
\hline Tresemme & 0,33 & 0,33 & 0 & 0 & 0 & 0 & 0,33 & 0 & 0 & 0 \\
\hline Rejoice & 0,45 & 0,09 & 0 & 0,09 & 0 & 0,09 & 0,27 & 0 & 0 & 0 \\
\hline Head \&Shoulders & 0,33 & 0,33 & 0 & 0 & 0,33 & 0 & 0 & 0 & 0 & 0 \\
\hline Dove & 0 & 0,09 & 0,18 & 0 & 0,09 & 0,27 & 0,27 & 0,09 & 0 & 0 \\
\hline Loreal & 0,2 & 0 & 0 & 0,2 & 0 & 0,2 & 0 & 0 & 0 & 0,4 \\
\hline Clear & 0,17 & $\overline{0,5}$ & 0 & 0 & 0 & 0 & 0,17 & 0,17 & 0,17 & 0 \\
\hline Lifeboy & 0,5 & 0 & 0 & 0 & 0 & 0 & 0,25 & 0,25 & 0 & 0 \\
\hline Lainnya & 0,25 & 0,25 & 0 & 0 & 0,25 & 0 & 0,25 & 0 & 0 & 0 \\
\hline $\begin{array}{l}\text { Konsumsi } \\
\text { Masing-masing } \\
\text { Merek Shampoo }\end{array}$ & 0,25 & 0,16 & 0,08 & 0,08 & 0,05 & 0,12 & 0,14 & 0,04 & 0,04 & 0,04 \\
\hline
\end{tabular}

Bila diasumsikan bahwa perpindahan merek shampoo stabil maka dapat dibuat matriks peluang transisi $\mathbf{P}$.

\begin{tabular}{|c|c|c|c|c|c|c|c|c|c|c|}
\hline & 1 & 2 & 3 & 4 & 5 & 6 & 7 & 8 & 9 & \\
\hline 1 & {$[0.30$} & 0.15 & 0.11 & 0.07 & 0.04 & 0.04 & 0.11 & 0.04 & 0.11 & 0 \\
\hline 2 & 0.1 & 0.15 & 0.12 & 0.15 & 0.08 & 0.19 & 0.08 & 0.00 & 00 & \\
\hline 3 & & 0.33 & 0.00 & 0.00 & 0.00 & 0.00 & 0.33 & 0.00 & & \\
\hline 4 & & 0.0 & 0.00 & 0.0 & 0.00 & 0.0 & 0.27 & 0 & & \\
\hline 5 & 0.33 & 0.33 & 0.00 & 0.00 & 0.00 & 0.33 & 0.00 & 0.00 & 0.00 & \\
\hline 6 & 0.00 & 0.09 & 0.18 & 0.00 & 0.09 & 0.27 & 0.27 & 0.09 & 0.00 & \\
\hline 7 & & 0.0 & 0.00 & 0.20 & 0.00 & 0.20 & 0.00 & 0.00 & 0.00 & \\
\hline 8 & 0.17 & 0.50 & 0.00 & 0.00 & 0.00 & 0.00 & 0.17 & 0.17 & 0.17 & \\
\hline 9 & & 0.0 & 0.0 & 0.0 & 0.0 & $0 .($ & & & 0.00 & \\
\hline & 25 & 0.25 & 0.00 & 0.00 & 0.25 & 0.00 & 0.25 & 0.00 & 0.00 & \\
\hline
\end{tabular}

Dengan matriks awal,

$$
x=\left[\begin{array}{llllllllll}
0,25 & 0,16 & 0,08 & 0,08 & 0,05 & 0,12 & 0,14 & 0,04 & 0,04 & 0,04
\end{array}\right]
$$

Matriks peluang transisi $\mathbf{P}$ diperoleh dari Tabel 3 yang dibuat dalam bentuk peluang. Pada matriks $\mathrm{P}_{11}$ diperoleh dengan membagi jumlah konsumen merek shampoo Sunsilk yang tidak berpindah dengan jumlah konsumen merek shampoo yang sebelumnya ya itu 8/27 $=0,3$ (dari Tabel 
3). Untuk nilai $\mathrm{P}_{12}$ diperoleh dari jumlah konsumen merek shampoo Sunsilk yang berpindah ke Pantene dibagi dengan jumlah konsumen merek shampoo Sunsilk sebelumnya yaitu 4/27 =0,15 (Tabel 3). Untuk seterusnya sampai $\mathrm{P}_{1010}$ berlaku hal yang sama, dimana diperoleh dari jumlah konsumen merek shampoo lainnya yang tetap menggunakan merek shampoo lainnya dibagi dengan jumlah merek shampoo lainnya pada periode sebelumnya yaitu $0 / 4=0$

Matriks $\boldsymbol{x}$ merupakan matriks kejadian atau matriks awal yang diperoleh dari Tabel 2 yang kemudian dibuat da lam bentuk peluang. Untuk merek shampoo Sunsilk, pada $x_{11}=0,25$ diperoleh dengan membagi jumlah konsumen merek shampoo Sunsilk dengan jumlah konsumen seluruhnya, yaitu $25 / 100=0,25$. Demikian seterusnya sampai dengan $x_{110}=0,04$ diperoleh dari jumlah konsumen merk shampoo lainnya dibagi dengan jumlah seluruh konsumen yaitu 4/100 =0,04.

Tabel 4. Prediksi Konsumsi Masing-masing Merek Shampoo pada Pelanggan Hypermart Swalayan Manado Town Square dari Tahun 2013 Sampai dengan Tahun 2016.

\begin{tabular}{|c|c|c|c|c|c|c|c|c|c|c|}
\hline \multirow[b]{2}{*}{ Tahun } & \multicolumn{10}{|c|}{ Persentase Merek Shampoo } \\
\hline & 兰 & 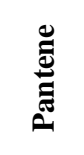 & & & 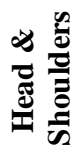 & ڤ̊ & 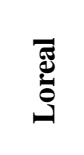 & 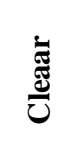 & 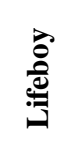 & 䒿 \\
\hline 2013 & 25 & 16 & 8 & 8 & 5 & 12 & 14 & 4 & 4 & 4 \\
\hline 2014 & 24,73 & 15,24 & 6,83 & 7,67 & 4,36 & 12,45 & 14,57 & 3,58 & 3,25 & 6,99 \\
\hline 2015 & 24,19 & 15,04 & 6,79 & 7,62 & 5,08 & 12,29 & 14,63 & 3,37 & 3,17 & 7,18 \\
\hline 2016 & 24,19 & 15,07 & 6,68 & 7,56 & 5,07 & 12,43 & 14,49 & 3,29 & 3,08 & 7,18 \\
\hline
\end{tabular}

Tabel 4 menunjukan bahwa proporsi konsumsi masing-masing penggunaan merek shampoo pertahun setiap kali mengalami transisi, dimana merek shampoo Sunsilk merek shampoo yang paling banyak diminati pada tahun 2013 mengalami penurunan $0,27 \%$ sehingga pada tahun 2014 menjadi $24,73 \%$ dan juga pada tahun berikutnya mengalami penurunan $0,54 \%$. Untuk merek shampoo Pantene, Tresemme, Rejoice, Clear dan Lifeboy mengalami penurunan pada tahun-tahun berikutnya yaitu Tresemme dari $8 \%$ pada tahun berikut turun menjadi $6,83 \%$, Pantene dari $16 \%$ turun menjadi $15,24 \%$, Rejoice dari $8 \%$ turun menjadi $7,67 \%$, Clear dari $4 \%$ turun menjadi 3,58\% dan Lifeboy dari $4 \%$ turun menjadi 3,25\%. Sedangkan untuk merek shampoo Dove, Loreal dan merek shampoo lainnya mengalami kenaikan yaitu Dove sebelumnya $12 \%$ naik menjadi $12,45 \%$, Loreal yang sebelumnya $14 \%$ naik menjadi $14,47 \%$ sedangkan untuk merek shampoo lainnya $4 \%$ naik menjadi 6,99\%.

\section{Kesimpulan}

Berdasarkan hasil analisis Rantai Markov dapat diketahui bahwa terjadi pergeseran konsumsi masing-masing merek shampoo dikalangan pelanggan Hypermart Swalayan MANTOS sebagai akibat dari perpindahan merek shampoo. Merek shampoo Sunsilk, Pantene, Tresemme, Rejoice, Clear dan Lifeboy mengalami penurunan setiap tahunnya. Merek shampoo Head and Shoulders mengalami penurunan pada tahun 2014 tetapi mengalami kenaikan pada tahun 2015 dan 2016. Merek shampoo Dove mengalami kenaikan pada tahun 2014 dan pada tahun 2015 mengalami penuranan tetap naik kembali pada tahun 2016. Merek shampoo Loreal mengalami kenaikan pada tahun 2014 dan 2015 tetapi mengalami penurunan pada tahun 2016. Merek shampoo lainnya mengalami kenaikan pada tahun 2014 dan 2015 tetapi jumlah konsumen pada tahun 2016 tidak mengalami kenaikan ataupun penurunan konsumen.

\section{Daftar Pustaka}

[1] Ching W.K. and Michael K.Ng. 2006. Markov Chain, Models, Algorithm and Application. Springer. United States Of America.

[2] Grimmet, GR. and Stirzaker, DR. 2001. Probability and Random Processes. Edisi ke-2. Clarendon Pres. Oxford. 
[3] Hatam, B. 2011. Analisis Rantai Markov dalam Memprediksi Perpindahan Merek Rokok [skripsi]. FMIPA UNSRAT. Manado.

[4] Howard, A. and Rorres, C. 2004. Aljabar Linier Elementer versi Aplikasi. Edisi ke-8, jilid 2. Terje mahan Izham Harme in dan Julian Gresdando. Elangga. Jakarta.

[5] Kasali, R. 1998. Membidik Pasar Indonesia Segmentasi, Targeting dan Positioning. PT.Gramedia Pustaka Utama. Jakarta.

[6] Ross, SM. 2007. Intorduction to Probablility Models. Edisi ke-9. Elsevier,Inc. Burlington.

[7] Sudijono, A. 2008. Pengantar Statistika Pendidikan. Raja Grafindo Persada. Jakarta. 